This article is (c) Emerald Group Publishing and permission has been granted for this version to appear here (http://epress.lib.uts.edu.au/research/handle/10453/4076). Emerald does not grant permission for this article to be further copied/distributed or hosted elsewhere without the express permission from Emerald Group Publishing Limited.' 


\title{
THE IMPACT OF ERP-SYSTEMS ON FIRM AND BUSINESS PROCESS PERFORMANCE
}

\author{
Authors: \\ Bernhard Wieder* \\ Peter Booth \\ Zoltan P. Matolcsy \\ Maria-Luise Ossimitz \\ Affiliation: \\ University of Technology, Sydney \\ Faculty of Business, School of Accounting
}

Address:

POBOX 123, Broadway

NSW 2007, AUSTRALIA

Tel/Fax/Email:

Tel: ++61 295143569

Fax: ++61 295143669

Bernhard.Wieder@uts.edu.au

* Author of Correspondence 


\title{
THE IMPACT OF ERP-SYSTEMS ON FIRM AND BUSINESS PROCESS PERFORMANCE
}

\begin{abstract}
The purpose of this article is to provide further insights into the adoption of enterprise resource planning systems (ERPS) and the impacts on organisational performance. It aims at challenging existing claims of ERP vendors with regards to the benefits of their products and at providing evidence of the benefits of bundling ERPS with supply chain management systems (SCMS).
\end{abstract}

A survey was conducted to collect data on several aspects of organisational performance in companies which adopted ERPS, SCMS and the respective control groups. Financial key performance indicators were used to measure overall firm performance and the Supply-Chain Operations Reference (SCOR) model to operationalise performance at the business process (supply chain) level.

Our key results contradict the claims of ERPS vendors insofar as we found no significant performance differences between ERPS adopters and non-adopters, neither at the core business process level, nor at the overall firm level. While we could confirm that, the longer the experience of firms with ERPS, the higher their overall performance, we found no evidence of a similar effect on business process (supply chain) performance. Only those ERPS adopters which also adopted SCMS achieved significantly higher performance at the business process level.

\section{KEYWORDS:}

Enterprise Resource Planning (ERP), Enterprise Systems, SCMS, IS-evaluation

\section{CLASSIFICATION:}

Conceptual article 


\section{INTRODUCTION}

The global success of Enterprise Resource Planning Systems (ERPS) has not only attracted the interest of researchers from the IT/IS-discipline, but from all major disciplines in business research - including accounting. The emergence of ERPS has moved the topic 'computerised business information systems' increasingly from the IT/IS domain to the business domain; from systems design and programming to business configuration, process mapping and reengineering. Using the systems development life cycle (SDLC) as conceptual reference, we observe that the efforts and weight of the critical success factors of ERPS projects (Sumner, M.,1999) moved from 'systems design' to 'systems implementation', and implementation teams are now usually led and dominated by classic business roles rather than IT-staff. ERPS impose their logic on organisations and often force employees to think in terms of integrated processes and to change the way they do accounting, production planning and control, etc.

All these changes brought about by ERPS made them a very 'attractive' research object of many business disciplines, and accounting is by nature the one from which we expect an answer to the question which ultimately counts in business: Are those systems worth the money?

Earlier approaches to this question identified non-financial performance measures as proxies for financial value (Bhatt, 2000, Beretta, 2002, Irani, 2002). Only relatively recently, the accounting discipline has come up with studies which for the first time provided evidence of the economic impacts of ERPS (Poston and Grabski, 2001, Matolcsy et al., 2002, Hunton et al., 2003, Nicolaou et al., 2003, Matolcsy et al., 2005). The results of those studies point into the same direction, but are not entirely consistent. They all find some evidence of immediate or delayed increases in firm performance after ERPS adoptions, but the performance increases identified are evident only in very few KPIs.

We argue that one of the reasons for these inconsistencies is that just relating 'ERPSadoption' to publicly available 'financial key performance indicators' (and controlling for some other dependent variables) fails to explain the increasing diversity and complexity 
of the life cycle of enterprise systems. In the emerging generation of enterprise application integration (EAI) enabled enterprise systems, traditional ERP-functionality cannot be isolated from the rest of the whole system and has to be evaluated in the broader context using a multi-dimensional system of performance measurement.

The purpose of this article is to provide further insights into the impacts of several aspects of ERPS adoption and ERPS use on firm performance and business process performance. It aims at challenging existing claims of ERP vendors with regards to the benefits of their products, and at providing evidence of the impact of bundling ERPS with supply chain management systems on performance.

We use ERPS adoption, ERPS history and ERPS extension (with a supply chain management system) as independent variables and KPIs for supply chain performance and firm performance as dependent variables.

Our key results contradict the claims of ERPS vendors insofar as we found no significant performance differences between ERPS adopters and non-adopters, neither at the supply chain level, nor at the overall firm level. While we could confirm that the longer the experience of firms with ERPS, the higher their overall performance, we could not confirm this effect with regards to business process (supply chain) performance. The latter result contradicts benefits widely associated with ERPS and supports the arguments in favour of the adoption of supply chain management systems (SCMS), because the latter proved to have a positive impact on business process (supply chain) performance in our study.

The main part of the article is structured as follows: First, we develop our research model and predictions (section 2), then we explain our research method and sample (section 3) and provide the results of our statistical analysis (section 4). The interpretations of the results and limitations are outlined in the concluding section (5). 


\section{RESEARCH FRAMEWORK AND MODEL DEVELOPMENT}

\subsection{Review of Literature on the Impact of ERPS on Performance}

Recent research on the impacts of ERPS on financial performance has found some evidence supporting the claim of all major ERPS vendors that their products enable companies to achieve "faster return on investment" (SAP, 2003a, and similar: SAP, 2003b, ORACLE, 2003a/b, and PEOPLESOFT, 2003).

Poston and Grabski (2001), for example, analyse four financial characteristics before and after ERP adoption using univariate tests. Their results indicate that ERP adoption leads to efficiency increase in terms of a reduction in employee numbers and in the ratio of employees to revenues for each year following the ERP implementation.

Hunton et al. (2003) provide evidence on the impact of ERPS adoption and overall firm performance by comparing return on assets, return on investments and asset turnover for ERP adopters and non-adopters. Their key results do not indicate a performance improvement for ERP adopters. However, they find that the financial performance of adopters has not declined during their test period, whilst the performance of nonadopters has declined during the same period.

Nicolaou et al. (2003) compare financial data of companies adopting enterprise wide systems and of a matched control group of firms. The results from a univariate analysis of performance differences across time periods show that firms adopting enterprise systems have significantly higher differential performance in their second year after the completion of the system than the control group.

All these recent examples of accounting research on the impact of ERPS on the performance of organisations provide valuable insights into a previously under-researched topic and they are similar in their approach in several ways: (a) They use only aggregated, publicly available financial accounting data to measure performance, (b) they do not clearly distinguish between overall firm performance and business process performance, and (c) the dependent variables used are essentially only ERPS adoption and the time of adoption. 
More recently, Matolcsy et al. (2005) performed a study using the same approach with regards to (a) and (c), however they extended the analysis of performance by also explicitly investigating financial performance indicators of core business processes in the value-chain. They found that the adoption of ERP systems leads to sustained operational efficiencies and improved overall liquidity. In addition, some support was found for increased profitability some time after the adoption of ERP, and for improvements in accounts receivable management.

While the approach in all these studies is similar, the results differ substantially. In the following sections, we elaborate a model which - as we argue - can provide deeper insights into some of the relationships between ERPS and performance by further refining the dependant variable 'ERPS' (see section 2.3) and by combining financial and nonfinancial performance measures in our analysis (see section 2.4).

\subsection{Model Foundations}

Like Matolcsy et al. (2005), we use the generic framework suggested by Dehning and Richardson (2002) as guidance for the development of our ERPS performance measurement model. Their framework classifies existing research on IT-performance measurement using 5 paths as shown in Figure 1. Based on a comprehensive review of the financial accounting and finance literature on IT-performance measurement, they demonstrate that most research in this field focuses on only one path (usually path 1), bypassing many other important factors. They also argue convincingly that this mainstream one-dimensional approach fails to explain IT-performance and leaves a gap between anecdotal evidence of IT-success and results of mainstream empirical research. The 'IT-productivity paradox' discussion and the often conflicting results of research following alternative paths in their framework can be quoted as the most important examples supporting their call for a more comprehensive 'multi-path' approach. 


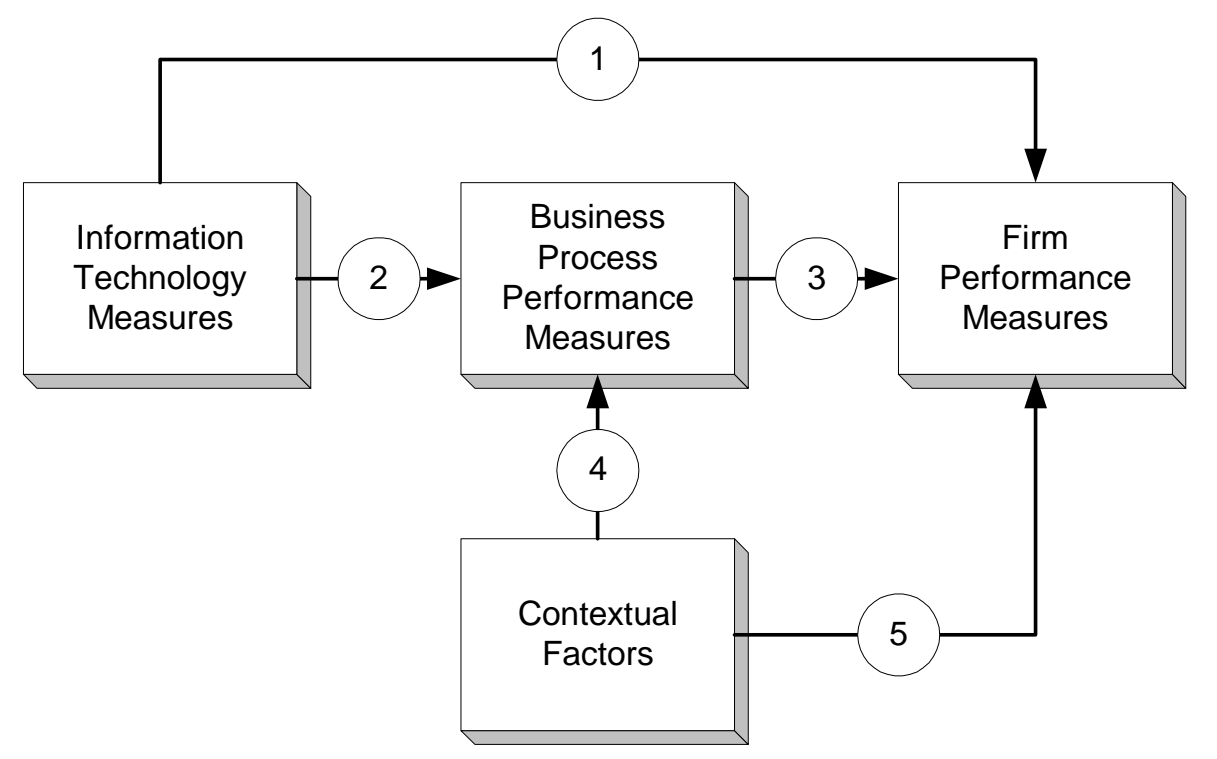

Figure 1: Framework for Evaluating Research on the Effects of IT Investments (Dehning and Richardson, 2002; simplified)

In the subsequent sections, we first operationalise the three objects in our model in the context of ERPS performance measurement: IT-measures, business process performance measures and firm performance measures. Then we make predictions about relationships (paths) between those objects.

\subsection{IT (ERPS) Measures Refined}

The definitions of ERPS used in literature vary slightly, but they all have one common theme: enterprise-wide integration of data/information and business processes. For Markus et al. (2000), for example, "ERP-systems are commercial software packages that enable the integration of transaction-oriented data and business processes throughout an organization", and according to Shang and Seddon (2002) "ERP software integrates management information and processes, such as financial, manufacturing, distribution and human resources, for the purpose of enterprise-wide management of resources". They also emphasise that ERPS are an example, but not the only form of 'enterprise systems' (ES). They discuss common features of enterprise software which are often associated with ERPS, ${ }^{1}$ such as 'set of packaged application software mod- 
ules', real-time information processing, based on deep knowledge of business practices gained by the vendors from their customers, semi-finished product which has to be configured, etc.

The first comprehensive empirical analysis of the performance of ERPS uses 'ERPS adoption' as the only independent variable, and then compares the performance of organisations pre and post-adoption (Poston and Grabski, 2001). Later research considers and investigates the time-factor in more detail, or more precisely: the time-difference between the adoption of an ERPS and when performance is measured (e.g. Hunton et al., 2003, Matolcsy et al., 2002, Nicolaou et al., 2003, Matolcsy et al., 2005). The results of this more recent research suggest the existence of a time-lag between the adoption of an ERPS and the realisation of benefits. We therefore include the time factor in our analysis of performance impacts of ERPS.

The second aspect of ERPS to be considered is the co-existence of other components of enterprise systems (ES), in particular specialised supply chain management systems (SCMS). Already back in 2001, a survey $(\mathrm{N}=89)$ in the US found that $59 \%$ of the respondents either had already or were planning to extend their ERPS with a SCMsolution. $84 \%$ of the respondents indicated that for any such expansion they would prefer to use the SCMS provided by their ERP-vendor (CIO magazine, 2001). SCMsoftware packages are more specialised forms of ES which integrate all logistics functions within organisations and usually also support inter-organisational business and systems integration (Tarn et al., 2002). In contrast to ERPS, SCMS usually comprise Advanced Planning Systems (APS) which support mathematical optimisation procedures and heuristics. Used in combination with ERPS, they partly substitute and partly complement ERPS functionality, with the level of substitution/complementation being primarily determined by the functionality of either package and partly by the preferences of the organisation using them.

We expect that the advanced features of SCMS and their functional focus lead to higher performance along the primary activities of the value chain (Porter, 1985), and used in conjunction with ERPS, to higher overall firm performance. 


\subsection{Business Process Performance Measures}

All major ERP-products on the market support 'logistics' (supply chain) processes and methods in operations management as part of their core-functionality. Therefore, we expect that the adoption of ERPS leads to better performance in terms of both primary and secondary ${ }^{2}$ (support) business processes in the value chain.

Financial KPIs are doubtlessly the most important and most widely used KPIs for firm performance, and they can also provide some valuable insights into business process performance (Dehning and Richardson, 2002, Matolcsy et al., 2005). These insights are, however, limited, especially if only publicly available data (from annual reports, etc.) are used. These highly aggregated data can only be used for a very general analysis of core processes in the value chain, e.g. the ability to turn over inventory quickly, but do not provide deeper insights into performance at the business process level (Kaplan and Norton, 1992). Obtaining these more detailed data on business process performance, however, requires research beyond secondary data analysis, i.e. a field study.

The operations management and supply chain management (SCM) literatures provide many examples of SC-performance measurement, and the Supply-Chain Operations Reference model (SCOR-model) published by the Supply Chain Council ${ }^{3}$ is considered to be an established model for measuring performance along this dimension; it will therefore be used for identifying and measuring business process performance in this study. The model comprises a mix of financial and non-financial measures for flexibility, reliability, responsiveness and costs/assets along the supply chain (see appendix). ${ }^{4}$

\subsection{Firm Performance Measures}

The empirical studies investigating the financial performance implications of ERPS use primarily financial ratios (and some limited market data). However, there is little overlap in terms of the precise measures used, as Table 1 illustrates. 


\begin{tabular}{|c|c|c|c|c|}
\hline Study & $\begin{array}{c}\text { Poston and } \\
\text { Grabski, } 2001\end{array}$ & $\begin{array}{c}\text { Hunton et al., } \\
2003\end{array}$ & $\begin{array}{c}\text { Nicolaou et al., } \\
2003 \\
\end{array}$ & $\begin{array}{c}\text { Matolcsy et al. } \\
2005\end{array}$ \\
\hline \multirow{7}{*}{$\begin{array}{c}\text { Measures } \\
\text { used }\end{array}$} & $\frac{\text { Residual Income }}{\text { Rt } 120 \%}$ & Return on Assets & Return on Assets & Net Profit Margin \\
\hline & SG\&A/Revenues & $\begin{array}{l}\text { Return on } \\
\text { Investments }\end{array}$ & $\underline{\text { Return on Sales }}$ & $\underline{\text { Current Ratio }}$ \\
\hline & COGS/Revenues & \multirow[t]{5}{*}{ Asset Turnover } & \multirow[t]{5}{*}{ Asset Turnover } & $\begin{array}{l}\text { Fixed Asset } \\
\text { Turnover }\end{array}$ \\
\hline & $\begin{array}{l}\text { Number of Em- } \\
\text { ployees/Revenues }\end{array}$ & & & $\begin{array}{l}\text { Sales Days } \\
\text { Outstanding }\end{array}$ \\
\hline & & & & Accounts \\
\hline & & & & Inventory \\
\hline & & & & $\begin{array}{c}\text { Turnover } \\
\text { Sales Change }\end{array}$ \\
\hline
\end{tabular}

SG\&A = Selling, General and Administrative Expenses; COGS = Costs of Goods Sold

Table 1: Financial and Market Performance Measurements used in Prior Literature

Interestingly, there is no agreement in the accounting literature with regards to which (of those) KPIs measure overall firm performance or business process performance best in the context of ERPS evaluation. There are even substantially different views as to whether certain KPIs measure firm performance or business process performance.

For classification purposes, follow the approach taken by Matolcsy et al. (2005), who use net profit margins and the current ratio as indicators of firm performance and fixed asset turnover, sales days outstanding, accounts payable days, inventory turnover and sales change as examples of process measures. Accordingly, we classify residual income, return on assets, return on assets, return on investments and return on sales as firm performance measures (underlined in Table 1), and all remaining measures as business process performance measures.

In contrast to the studies mentioned above, we use a field study (survey), which gives us more flexibility with regards to the selection of financial performance measures, because we do not have to rely on publicly available financial data. In addition, we are able to include respondents perceptions about their companys' performance compared to other firm's in their industry. We use ROI as indicator of the profitability of the capital employed and operating profits as an absolute ${ }^{5}$ KPI of profitability. Non-operating re- 
sults are excluded, because we do not think that they are influenced by ERPS. We also include the dynamic components of operating profits, viz. sales growth rate and cost reduction. In addition to these accrual performance measures, we include cash flow as an indicator of a firm's performance in terms of liquidity (Matolcsy et al., 2002).

\subsection{Predictions}

As mentioned in the introduction, our key objective is to investigate impacts of several aspects of ERPS adoption on firm performance and business process performance. We use ERPS adoption, ERPS history and 'ERPS extension with a SCMS' as independent variables and KPIs for supply chain performance and firm performance as dependent variables.

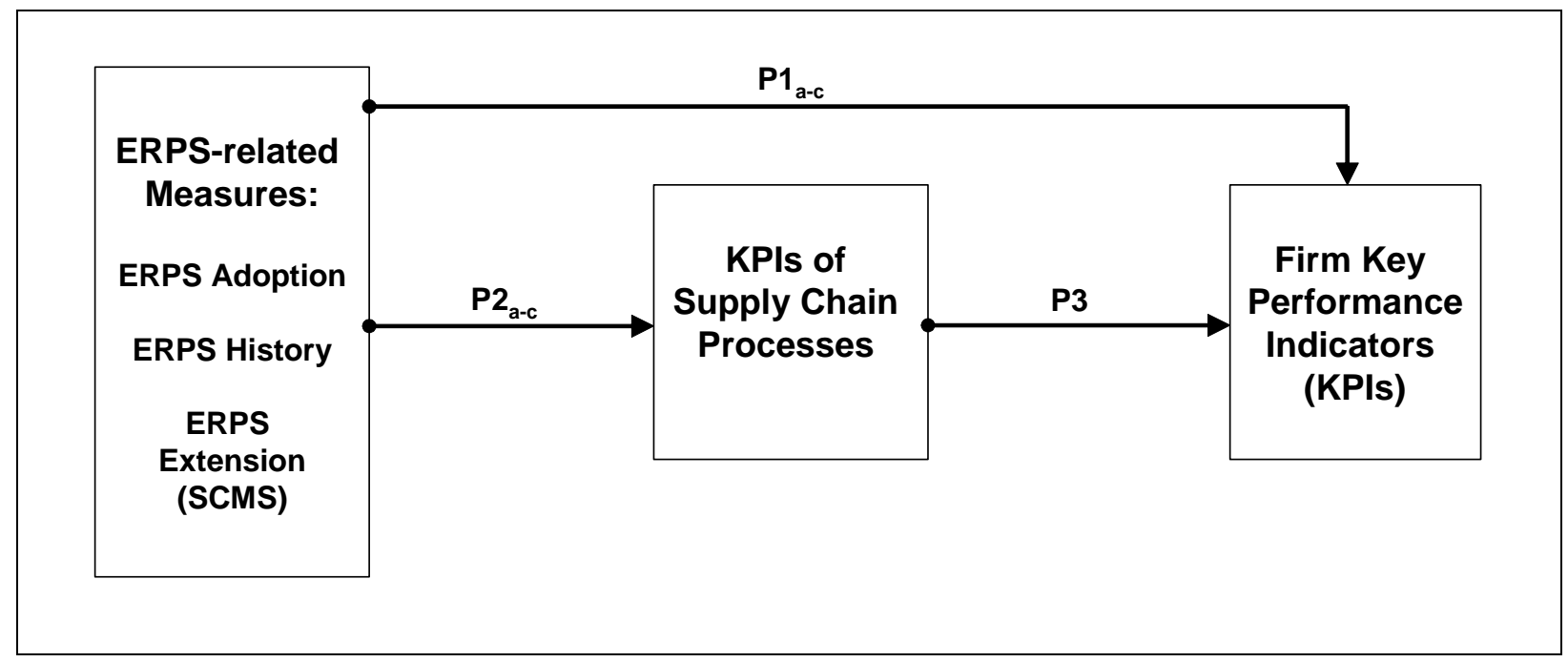

Figure 2: Research Model

The model shown in Figure 2 comprises all main relationships investigated in our study.

Our model development leads to the following predictions:

P1a: We predict better firm performance for ERPS users than for non-ERPS users.

P1b: For ERPS users we predict that the longer the experience with ERPS, the better their firm performance.

P1c: $\quad$ We predict better firm performance for ERPS users extending their ERPS with SCMS than for ERPS users that do not. 
P2a: We predict better supply chain performance for ERPS users than for non-ERPS users.

P2b: For ERPS users we predict that the longer the experience with ERPS, the better their supply chain performance.

P2c: We predict better supply chain performance for ERPS users extending their ERPS with SCMS than for ERPS users that do not.

P3 (control): We predict a positive impact of supply chain performance on firm performance.

\section{RESEARCH METHOD}

\subsection{Sample and Descriptive Statistics}

In March 2001, a questionnaire was mailed out to the Chief Information Officer (or equivalent) of 2,170 Australian companies sourced from the Australian Business Journal 'BRW' top-500 list and a 'Connect4' database. The large target sample was used to identify a sufficiently comprehensive set of firms who were either using or intending to use both ERPS and SCMS. A follow up letter was sent to all non-respondents in April. 68 responses to this first stage of the survey were received by the third week of April. As 296 questionnaires were returned by Australia Post due to incorrect addresses, the actual sample size was 1,874 firms. The low response rate might have been due to 'over-surveying' in Australia's industry, the length of survey, but also to errors in the underlying address databases. ${ }^{6}$

In this second stage, a telephone survey, we had to exclude several sections from our questionnaire which was too long for a telephone survey. Accordingly, we had to drop some research questions we had initially set up. The sample for stage 2 was selected from the initial large sample reduced by all companies which had either responded already or had moved location. Out of this sample, we selected those 49 firms who had responded to a previous survey on similar topics. ${ }^{7} 38$ of those firms participated in the second stage of the survey. The final sample of respondents comprised 106 companies or $5.7 \%$ of the actual sample size. 
During the process of data entry, another 4 companies had to be eliminated due to clearly inconsistent data or irrelevance for this study (non-profit organizations). So the final sample used for our analysis comprised 102 companies from all sectors of the economy (see Table 2).

\begin{tabular}{|c|c|}
\hline Industry & Percent \\
\hline Diversified Resources/Mining & $15.7 \%$ \\
\hline Others (Primary Sector) & $1.0 \%$ \\
\hline Energy & $2.9 \%$ \\
\hline Total: Primary Sector & $19.6 \%$ \\
\hline Assembly-Line Production & $5.9 \%$ \\
\hline Batch Production & $13.7 \%$ \\
\hline Process Production & $10.8 \%$ \\
\hline Project/Unit Production & $1.0 \%$ \\
\hline Total: Secondary Sector & $31.4 \%$ \\
\hline Retail/Wholesale and Transport & $18.6 \%$ \\
\hline Consulting & $2.0 \%$ \\
\hline Financial Services, Banking/Finance, Insurance & $11.8 \%$ \\
\hline Healthcare, Tourism and Leisure & $6.9 \%$ \\
\hline Media, Telecommunications, Software, IT-Services & $2.9 \%$ \\
\hline Property, Infrastructure and Facilities & $1.0 \%$ \\
\hline Others (Services Sector) & $5.9 \%$ \\
\hline Total: Tertiary Sector & $49.0 \%$ \\
\hline
\end{tabular}

Table 2: Industry Classification of Respondents

All primary sector, manufacturing sector and retail/wholesale companies (69.6\%) were considered to be eligible for testing predictions $1 \mathrm{c}, 2 \mathrm{c}$ and 3 . In this article, we refer to this sample as 'SCM-companies'.

The average operating revenue in the financial year preceding the survey was Mio $A \$ 7,506$ and the average number of full-time employees (or equivalents) was 6,683 . The average number of regular suppliers $(2,832)$ and customers $(276,688)$ were relatively large, considering the relatively small size of the Australian market and economy. $48 \%$ of the respondents indicated that their company was fully Australian owned, $20 \%$ were majority Australian owned, and $23 \%$ were either dominated or fully owned by a foreign entity. The remaining $9 \%$ of respondents to the survey did not answer this question. 


\subsection{Measures of Key Variables}

The selection criteria for the key variables used in our study have already been discussed in detail. In this section, their actual measurement is explained.

Respondents were provided with a short version of our definition of ERPS and were asked whether they had ever considered implementing such a system. If so, their ERPS status was categorised as follows: (1) 'System analysis is still in progress', (2) 'rejection', (3) 'implementation is still in progress' or (4) 'have adopted and 'gone-live'. Only go-live companies (4) were included in the test group for P1a and P2a. Implementers (3) were excluded from our analysis, because we considered them to be in a transition state which qualified them neither as ERPS users nor as non-users. Respondents who ticked either (1) or (2) were treated as non-users. The same set of questions was used to categorise respondents in terms of SCMS-use. ${ }^{8}$

We also asked ERPS users to provide us with the go-live year and month, the ERPS vendor and product name, the current version/release and details on the modules used at the time the survey was conducted. This information was used to verify the ERPS status and to provide the basis for generating a measure of ERPS history.

All ERP products from vendors other than the 'big-3' were verified to ensure that they really met the definition of ERPS used in our research. 3 respondents who claimed to be ERPS users had to be eliminated from this group after this investigation. The final sample contained 49 (48\% of 102) ERPS users and 40 (39.2\%) non-users. 9 respondents were just in the implementation process and 4 did not answer this question. Hence, the ratio of companies in the test-group for $\mathrm{P} 1 \mathrm{a}$ and $\mathrm{P} 2 \mathrm{a}$ to those in the control group was 55.1 to 44.9 .

As mentioned earlier in this article, five firm KPIs were selected with reference to earlier accounting literature. Respondents were asked to rate their comparative firms' performance on those criteria on a 7 -point Likert scale $(1=$ not at all satisfactory, $7=$ outstanding).

The same scale was used to measure the performance at the business process/supply chain level. Those questions were derived from the SCOR-model, which contains sup- 
ply chain measures from four areas: Flexibility, reliability, responsiveness and costs/assets. Only the responses of SCM-companies were used in our tests of P1c, P2C and P3 (see appendix for details).

\section{STATISTICAL ANALYSIS AND RESULTS}

\subsection{Statistical Analysis}

\subsubsection{Performance of ERPS users and non-ERPS users (P1a \& P2a)}

In our first analysis, we tested for differences between ERPS users (49 valid responses) and non-users (40) with regards to the two levels of performance identified in our model (prediction $1 \mathrm{a} \& 2 \mathrm{a}$ ). As the test for normal distribution of the test group and control group was negative, nonparametric two-independent sample tests (Mann-Whitney $U$ Test and Two-Sample Kolmogorov-Smirnov Test) were used.

Table 3 summarises the results of our tests of $\mathrm{P} 1 \mathrm{a} \& 2 \mathrm{a}$. Despite the fact that ERPS users on average scored clearly higher in all dimensions of performance, we could not find any significant differences between the two samples, neither in terms of firm performance, nor in terms of performance along the supply chain. Even a 1-tailed interpretation of our tests does not change this fact.

\begin{tabular}{|r|c|c|}
\hline Grouping Variable: ERPS use & Firm (Financial KPIs) & $\begin{array}{c}\text { Supply Chain } \\
\text { KPIs }^{\times}\end{array}$ \\
\hline Mann-Whitney U & 841.5 & 242.5 \\
\hline Wilcoxon W & $1,661.5$ & 395.5 \\
\hline Z & -0.841 & -1.073 \\
\hline Asymp. Sig. (2-tailed) & 0.400 & 0.283 \\
\hline $\mathrm{N}$ & 87 & 52 \\
\hline
\end{tabular}




\begin{tabular}{|r|c|c|}
\hline & Firm (Financial KPIs) & $\begin{array}{c}\text { Supply Chain } \\
\text { KPIs }^{\times)}\end{array}$ \\
\hline Kolmogorov-Smirnov Z & 0.717 & 0.847 \\
\hline Asymp. Sig. (2-tailed) & 0.683 & 0.470 \\
\hline $\mathrm{N}$ & 87 & 52 \\
\hline
\end{tabular}

${ }^{\mathrm{x})}$ Only SCM-companies included.

Table 3: Mann-Whitney U Test and Two-Sample Kolmogorov-Smirnov Test for ERPS/non-ERPS

These overall results are partly contradicting those of recent studies quoted in the literature review, which actually concluded that there are some significant differences in financial performance between ERPS adopters and non-adopters (Hunton et al., 2003, Nicolaou et al., 2003, Matolcsy et al., 2005). What was even more surprising was the fact that ERPS users did not score significantly higher than the control group in the area of logistics/supply chain management, one of the core domains of ERPS. A closer look at all individual scores within the aggregate measure supply chain KPIs revealed that ERPS users did actually score higher in all 23 individual KPIs, but it also shoed that these differences were only significant in the following 4 individual categories (at the 0.05-level): Relative level of manufacturing labour costs, relative level of finished goods inventory holding costs, time required to produce an item and percentage of shipping errors.

In the case of firm performance indicators, the ERPS users also showed higher means in all individual categories, but none of these differences were significant. We expected further insights into the reasons for the partly surprising results by testing for performance differences with regards to ERPS history and ERPS adoption (use).

\subsubsection{ERPS History and Performance (P1b and P2b)}

Two types of tests were performed to identify differences between companies with longer ERP-experience and more recent adopters. In the first test, an ERPS history scale was used which measures the number of months between the go-live date and the day the survey was completed. As the observations on this scale were normally distributed, we used standard correlations (Pearson, Kendall and Spearman) to test our predications. 
The results of this first test confirm our predictions with regards to the relationship between ERPS history and firm performance, but not about the impact of ERPS history on supply chain performance.

\begin{tabular}{|l|l|c|r|}
\hline \multicolumn{2}{|l|}{ ERPS use in months } & $\begin{array}{c}\text { Firm (Financial } \\
\text { KPIs) }\end{array}$ & $\begin{array}{c}\text { Supply Chain } \\
\text { KPIs }^{\times)}\end{array}$ \\
\hline \multirow{2}{*}{$\begin{array}{l}\text { Pearson } \\
\text { Correlation }\end{array}$} & Correlation Coefficient & $\mathbf{0 . 3 9 4 ^ { * * }}$ & 0.173 \\
\cline { 2 - 4 } & Sig. (1-tailed) & 0.004 & 0.143 \\
\cline { 2 - 4 } & $\mathrm{N}$ & 44 & 40 \\
\hline \multirow{3}{*}{ Kendall's tau_b } & Correlation Coefficient & $\mathbf{0 . 2 4 3}$ & 0.073 \\
\cline { 2 - 4 } & Sig. (1-tailed) & 0.012 & 0.278 \\
\cline { 2 - 4 } & $\mathrm{N}$ & 44 & 33 \\
\hline \multirow{3}{*}{ Spearman's rho } & Correlation Coefficient & $\mathbf{0 . 3 8 2 ^ { * * }}$ & 0.061 \\
\cline { 2 - 4 } & Sig. (1-tailed) & 0.005 & 0.368 \\
\cline { 2 - 4 } & $\mathrm{N}$ & 44 & 33 \\
\hline
\end{tabular}

* Correlation is significant at the 0.05 level (1-tailed).

** Correlation is significant at the 0.01 level (1-tailed).

x) Only SCM-companies included.

Table 4: Correlations for ERPS history and Performance

In the second test, we split the group of ERPS users into 2 sub-groups of 'mature ERPS users' and 'recent ERPS adopters'. We used the median (5 years) as a cut-off point, which also complies with recent research which suggests that there is a time-lag of benefit realisation and that the positive impact on performance starts to become significant after 2-3 years and tends to increase over years. The results of the nonparametric two sample tests confirmed the results of the correlations shown in Table 4.

For the reasons mentioned in section 2.4, the weak impact of ERPS history on supply chain performance was surprising. So we hoped to gain further insights into this result by comparing the performance scores of ERPS users with SCMS (test group) and without (control group).

\subsubsection{ERPS Extensions (SCMS) and Supply Chain Performance (P1c \& P2c)}

Due to the short history of SCMS, especially in Australia, only 7 organisations in our sample had adopted SCMS by the time the survey was conducted, 6 of which also used ERPS. This very small sample size eliminates statistical explanatory power from this analysis. However, the results of our statistics might still at least give useful indications 
and provide paths for future research. The results of the independent sample statistics are depicted in Table 5. In the absence of positive results from tests for normal distribution, nonparametric two-independent sample tests were used again.

\begin{tabular}{|c|c|c|}
\hline $\begin{array}{l}\text { Grouping Variable: } \\
\text { SCMS \& ERPS use }\end{array}$ & Firm (Financial KPIs) & $\begin{array}{l}\text { Supply Chain } \\
\text { KPIs }\end{array}$ \\
\hline Mann-Whitney U & 130.0 & 34.5 \\
\hline Wilcoxon W & 964.0 & 737.5 \\
\hline Z & -0.640 & -2.253 \\
\hline Asymp. Sig. (2-tailed) & 0.522 & $0.024^{*}$ \\
\hline $\mathrm{N}$ & 6 & 6 \\
\hline Kolmogorov-Smirnov Z & 0.670 & 1.418 \\
\hline Asymp. Sig. (2-tailed) & 0.761 & $0.036^{*}$ \\
\hline $\mathrm{N}$ & 6 & 6 \\
\hline
\end{tabular}

* Significant at the 0.05 level (1-tailed).

** Significant at the 0.01 level (1-tailed).

Table 5: Extended ERPS (ERPS + SCMS)

These results provide an indication that ERPS users that also adopted SCMS perform by far better along the supply chain (mean 5.0) than ERPS users which did not use additional SCMS (mean 4.24). However, we could not confirm prediction 1c, viz that the adoption of a SCMS in a ERPS user company also directly leads to firm performance increases.

\subsubsection{Supply-Chain Performance and Firm Performance (P3)}

Prediction 3 was tested only for control purposes rather than for gaining new insights, because unless important additional factors impact negatively on firm performance, high performance in the core business processes would very likely lead to higher firm performance. Correlation results indeed confirmed out predication (1-tailed):

- Pearson Correlation: 0.363, $p=0.007$

- Kendall's tau_b: $0.213, p=0.024$

- Spearman's rho: 0.304, $p=0.022$

\subsection{Summary of Main Results}

Figure 3 summarises the main results of our analysis. We found no support for our prediction that ERPS users will have significantly higher performance scores at both the 
core business process level and at firm level (P1a and P2a). However, we confirmed that longer experience with ERPS has a positive impact on firm performance and that ERPS extended by SCMS positively impact on business process performance (supply chain KPIs). The latter result, however, is only indicative due to a very small sample size.

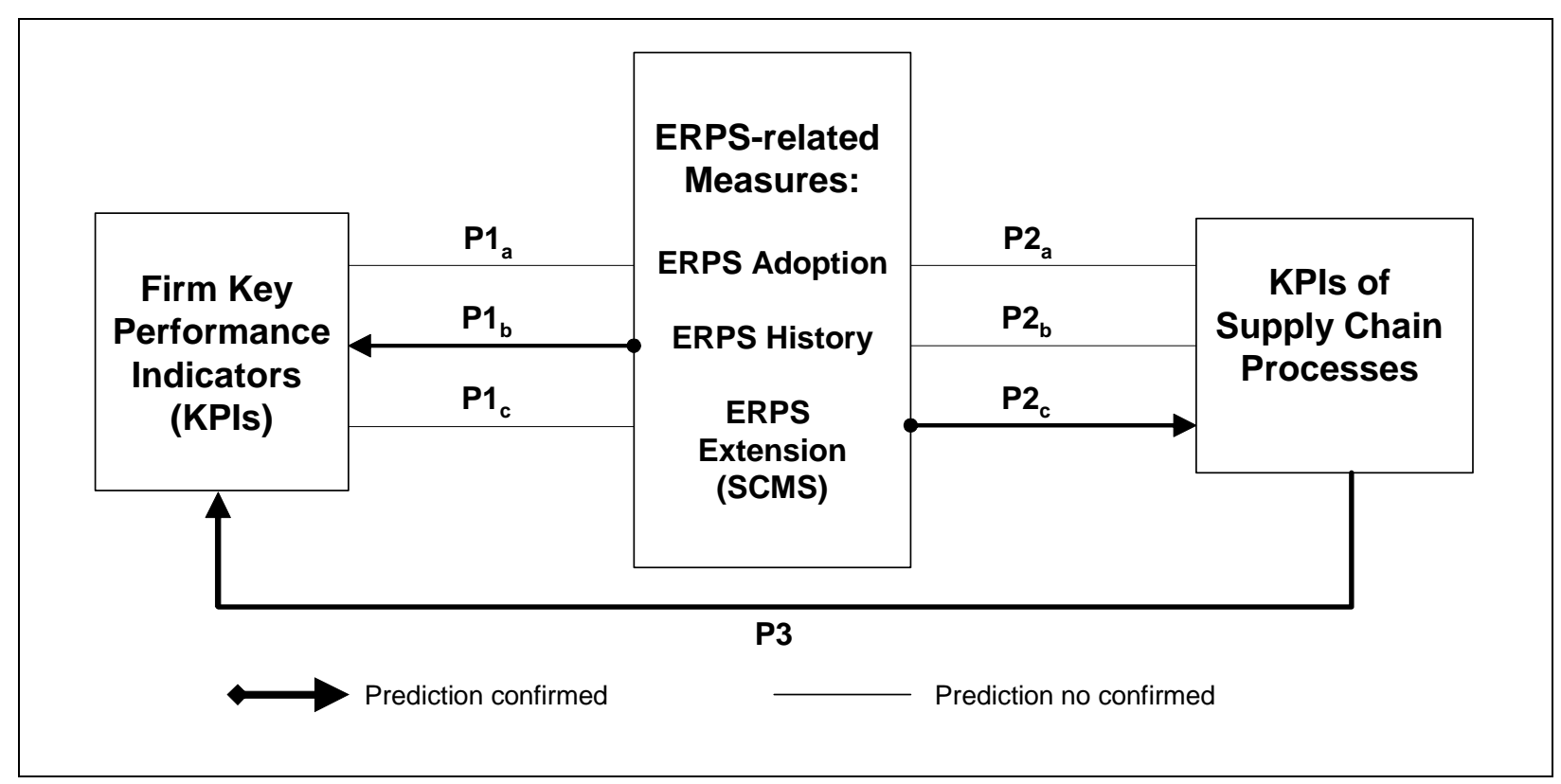

Figure 3: Summary of Main Results 


\section{CONCLUSIONS, LIMITATIONS AND FUTURE RESEARCH}

The main objective of this article was to investigate impacts of several aspects of ERPS adoption and use on firm performance and business process performance. We use ERPS adoption, ERPS history and ERPS extension (with a SCMS) as independent variables and KPIs for supply chain performance and firm performance as dependent variables.

Perception-based measures were used to capture both financial and non-financial performance indicators. We used independent samples tests to identify performance differences between ERPS users and non-ERP users, and we then analysed performance differences within the groups of ERPS users based on two criteria: ERPS history and the extension of the ERPS using SCM-software. This study is the first empirical study investigating the impact of several aspects of ERPS-adoption on both core business processes (supply chain performance) and overall firm performance.

Probably the most striking result was that we did not find any significant performance differences between ERPS adopters and the control group - neither at the supply chain level, nor at the overall firm level. However we found that the longer ago an ERPS was initially implemented, the higher the overall firm performance, but - again surprisingly not the supply chain performance.

One of the explanations for the absence of a positive impact on firm performance in the shorter run offered in literature is that the costs of the ERPS investment tend to exceed short and medium-term productivity increases (Dehning and Richardson, 2002). While our findings partly support this argument, they also reveal that even companies who have implemented ERPS long ago do not perform better in their core business processes (supply chain) than companies with a shorter ERPS history (and non-ERPS adopters). We can summarise that the ERPS-users in our study failed to achieve higher supply chain performance, both in the short and long-term, and they failed to achieve higher overall firm performance, although the latter improved with time since the adoption; as this improvement is not due to improvements in core business processes, it is supposedly due to improvements in supporting functions in the value chain (Porter, 
1985). Finally, we found some evidence supporting our prediction that extending ERPS with additional solutions for supply chain management actually has a positive impact on an organisation's performance along the supply chain.

We acknowledge that there are several limitations to our research, the most important one being the low response rate to our survey and the small sample size. We are aware that this limits explanatory power of our results.

We also made some observations which are not explicitly included in our analysis, but which might also create incentives for further research. We noticed, for example, that there is some confusion about the term ERPS and its relation to other forms of enterprise systems. We assume this confusion is stimulated by the ERP-vendors in 2 ways: On the one hand, we found that more and more vendors of small functional software packages seem to use the label 'ERP' inappropriately, e.g. for small accounting packages with integrated inventory management. On the other hand it is observed that the large ERP-vendors SAP, Oracle and Peoplesoft start to change their interpretation and use of the term ERP and package their traditional products in a variety of solutions, which make it increasingly difficult to classify them as ERP, SCM, CRM, etc. In fact, future research in 'enterprise systems' will have to redefine its underlying typologies of enterprise systems based on this ongoing changes in the business systems landscape. This will open a pathway for research into e.g. the 'optimum' scope of integration and advantages and disadvantages of various integration approaches (ERPS, SCMS, CRMS, DW, Enterprise Application Integration, etc.). 


\section{REFERENCES}

Beretta, S. (2002), "Unleashing the integration potential of ERP systems: the role of process-based performance measurement systems", Business Process Management Journal, Vol. 8 No. 3, pp. 254-277.

Bhatt, G.D. (2000), "An empirical examination of the effects of information systems integration on business process improvement", International Journal of Operations and Production Management, Vol. 20 No. 11, pp. 1331-1359.

Booth, P., Matolcsy, Z. and Wieder, B. (2000), "The impacts of enterprise resource planning systems on accounting practice - the Australian experience", Australian Accounting Review, Vol. 16, pp. 4-18.

CIO Magazine (2001), "ERP progress report", http://www2.cio.com/research (accessed on 13/05/2004).

Dehning, B. and Richardson, D.J. (2002), "Returns of investments in information technology: a research synthesis", Journal of Information Systems, Vol. 16 No. 1, pp. 7-30.

Hunton, J.E., Lippincott, B. and Reck, J.L. (2003), "Enterprise resource planning (ERP) systems: comparing firm performance of adopters and non-adopters", International Journal of Accounting Information Systems, Vol. 4, pp. 165-184.

Irani, Z. (2002), "Information systems evaluation: navigating through the problem domain", Information and Management, Vol. 40, pp. 11-24.

Kaplan, R.S. and Norton, D.P. (1992), "The Balance Scorecard - measures that drive performance", Harvard Business Review, January-February, pp. 71-79.

Lee, Z. and Lee, J. (2000), "An ERP implementation case study from a knowledge transfer perspective", Journal of Information Technology, Vol. 15, pp. 281-288.

Markus, M.L., Axline, S., Petrie, D. and Tanis, C. (2000), "Learning from adopters' experience with ERP problems encountered and success achieved", Journal of Information Technology, Vol. 15 No. 4, pp. 245-265.

Matolcsy, Z., Booth, P. and Wieder, B. (2002), "The economic benefits of enterprise resource planning systems: some empirical evidence", AAANZ Conference, Perth, July. 
Matolcsy, Z., Booth, P. and Wieder, B. (2005), "The economic benefits of enterprise resource planning systems: some empirical evidence", Journal of Accounting and Finance, 2005 (forthcoming).

Nicolaou, A.I., Stratopoulos, T. and Dehning, B. (2003), "Financial analysis of potential benefits from ERP systems adoption", Journal of Business and Information Technology, pp. 40-50.

Oracle (2003a), "E-Business Suite", www.oracle.com/applications/ (accessed on 8/8/03).

Oracle (2003b), "Oracle Customers", www.oracle.com/customers/index.html?ebsquotes.html/ (accessed on 8/8/03).

Peoplesoft (2003), www.peoplesoft.com/corp/en/products/line/scm/inv_plan/ (accessed on $8 / 8 / 03)$.

Porter M.E. (1985), Competitive advantage: creating and sustaining superior performance, Free Press, New York/ London.

Poston, R. and Grabski, S. (2001), "Financial impact of enterprise resource planning implementations", International Journal of Accounting Information Systems, Vol. 2 No. 4, pp. 271-294.

SAP AG (2003a), "Benefits of ERP", www.sap.com/solutions/erp/businessbenefits/ (accessed on 8/8/03).

SAP AG (2003b), "ROI of integrated SAP solutions (Netweaver)", www.sap.com/solutions/netweaver/businessbenefits/roi.asp (accessed on 8/8/03).

Shang, S. and Seddon, P. (2002), "Assessing and managing the benefits of enterprise systems: the business manager's perspective", Information Systems Journal, Vol. 12, pp. 271-299.

Sumner, M. (1999), "Critical success factors in enterprise wide information management systems projects", Americas Conference on Information Systems, Milwaukee, USA.

Tarn, M., Yen, D. and Beaumont, M. (2002), "Exploring the rationales for ERP and SCM integration, Industrial Management and Data Systems", Vol. 102 No. 1, pp. 2634. 


\title{
7. APPENDIX: COMPONENTS OF AGGREGATED KPIS
}

The scores for firm performance were obtained asking the following question:

Please rate your firm's performance on the criterion $(1=$ not at all satisfactory, $4=$ satisfactory, 7 = outstanding).

\author{
Return on investment \\ Operating profits \\ Sales growth rate \\ Cost reduction programs \\ Cash-flow \\ (etc.)
}

The measurement of the SCM-KPIs was based on the following question:

Please rate your firm's performance in the following attributes compared to other similar firms (1 $=$ not at all satisfactory, $4=$ satisfactory, 7 = outstanding).

Relative level of logistics and distribution costs

Relative level of manufacturing labour costs

Relative level of maintenance costs

Relative level of re-work costs

Relative level of materials inventory holding costs

Relative level of obsolete inventory costs

Relative level of work in progress inventory costs

Relative level of finished goods inventory holding costs

Speed at filling orders

Percentage of deliveries made on time

Stockout probability

Backorder level

Time required producing an item

Percentage of shipping errors

Percentage of customers who complain

The extent to which we can change the output level of products produced

The ease with which we can change the output level of products produced

The extent to which we can change planned delivery dates

The ease with which we can change planned delivery dates

The extent to which we can change the variety of products produced

The ease with which we can change the variety of products produced

The extent to which we can introduce and produce new products

The ease with which we can introduce and produce new products 
$1 \quad$ Similar examples are provided by Lee and Lee (2000) and Tarn et al. (2002).

2 Secondary (support) processes such as accounting, IT, human resource management, are not considered in this study.

3 www.supply-chain.org

$4 \quad$ The individual performance indicators are listed in the appendix.

5 The measure was, however, relative in the sense that we asked respondents to benchmark their company against the industry.

6 The fact that 269 questionnaires were returned by the receivers because of the addressed companies having moved location gave reason to assume that a very large number of other questionnaires has not reached the addressee, but was not 'voluntarily' returned by the receiver. This assumption was confirmed in the second stage of the survey, a telephone survey, which revealed that many of the addressees selected in this second stage had never received the questionnaire by mail, although we had not got their letters back marked 'return to sender'.

$7 \quad$ See Booth et al. (2000) for details.

8 We also tried to identify CRMS-users and DW-users into our survey, but had to later exclude this section due to many incomplete answers. 